\title{
The use of indicator paddocks to improve the quality of information for grazing management
}

\author{
M.B. De FREITAS', E.M. HURLEY ${ }^{2}$ and W.J. PARKER ${ }^{2}$ \\ Porto Allegre, RS, Brasil
}

${ }^{2}$ Department of Agricultural and Horticultural Systems Management, Massey University, Palmerston North

\begin{abstract}
Data to estimate changes in average pasture cover (APC) provide valuable information to the farm manager for planning and controlling grazing decisions, but may be time consuming to collect. The more frequently the information is obtained the more often can adjustments be made towards attaining targets. APC estimated by sampling a small percentage of the paddocks (indicator paddocks) was compared with estimates based on measurements of the whole farm, as a means of providing reliable and timely pasture budgeting information for the manager of a bull beef unit. Some combinations of indicator paddocks reliably reflected whole-farm-based estimates $(r=0.75$ 0.99 ) but were not always practical, or less time consuming, to collect. Application of the indicator paddock technique was estimated to increase annual data collection costs by $\$ 300$ on the case study farm.
\end{abstract}

Keywords: bull beef, feed budgeting, indicator paddocks, pasture cover

\section{Introduction}

Various researchers have argued that the process of setting physical targets for grazing management and regularly monitoring progress towards those targets can improve farm performance (e.g., Ridler \& Hurley 1984). However, on many farms, large numbers of paddocks or difficult terrain make a regular wholefarm pasture monitoring programme-impractical. Piggot (1986) obtained satisfactory estimates of dairy farm average pasture cover (APC) by averaging the measurements from paired groups of the highest- and lowest-yielding paddocks. These were referred to as indicator paddocks. Estimating APC from measurements on a small sample of paddocks, instead of the whole farm, was simpler and less time consuming than measuring all paddocks, yet was accurate enough for monitoring progress in implementing grazing plans. On non-dairy livestock farms there are often more mobs of grazing stock, and the topography can be less uniform. This may make the sampling technique difficult to apply. The objective of this study was to identify practical ways of applying the indicator paddock technique under a more complex measurement situation on a bull beef farm.

\section{Materials and method}

The case farm

The Tuapaka Bull Beef Farm, which has been run as a bull beef unit since 1983, was used as a case study (McRae \& Morris 1983). An intensive monitoring system, including monthly measurement of pasture levels and animal growth rates, as well as rainfall and daily temperatures, is a feature of management. Bulls are set stocked from spring to early autumn, but during late autumn and winter, when the growth of pasture is slower and less certain, a form of rotational grazing $(\mathrm{RG})$ is used to improve the manager's control over animal intake and sward condition (Grant et al. 1992). Groups of bulls $(n=4,5)$, selected on liveweight in March, are then each grazed rotationally on a pre-determined area until pasture dry matter accumulation exceeds livestock demand in spring. At this time bulls are setstocked (SS) to allow ad lib. feeding and the annual grazing management cycle is repeated. If fighting occurs while bulls are in mobs, problem bulls are removed and grazed separately in one or more SS groups. Thus, during winter there will be between 5 and 9 mobs of grazing animals.

Although APC was measured monthly, the corresponding targets were expressed fortnightly. The manager's opinion was that adverse changes in APC could occur, but not be detected in time under the monthly monitoring programme (see-for example Figure 1). However, taking fortnightly measurements from the 31 paddocks to calculate whole farm APC would be too time consuming and was likely to have a high opportunity cost. In this situation, the indicator paddock technique appeared to have the potential to supply the necessary pasture cover information to the manager.

Pasture data collection

Data to calculate whole farm APC were collected at fortnightly intervals from May to August 1992 with a rising plate meter (RPM) (Earle \& McGowan 1979). Forty RPM readings per paddock were recorded, and 
pasture cover for each paddock was calculated from a linear regression equation:

$$
\begin{aligned}
& \mathrm{y}_{\mathrm{i}}=158 \times \text { RPM reading }+117 \\
& \mathrm{APC}=\sum_{i=1}^{n} \mathbf{y}_{\mathbf{i}} \mathrm{a}_{\mathbf{i}} / \Sigma \mathrm{a}_{\mathbf{i}}
\end{aligned}
$$

where $\quad \mathbf{y}_{\mathbf{i}}=$ pasture cover in the ith paddock

at = effective grazing area in the ith paddock

$n=$ number of paddocks (31)

\section{Sample selection}

A range of samples of indicator paddocks was selected from the data set describing estimates of APC for each paddock. The first set of samples was selected to correspond to Piggot's (1986) technique as outlined in Table 1. Some of the samples selected in this set are impractical to collect regularly because in order to determine which paddocks in each RG group have the most and least pasture, a high proportion of paddocks would have to be measured. In other cases, the paddock groupings would mean that most of the farm would have to be traversed to collect the data. For these reasons a second set of more practically collected samples was selected. These comprised those paddocks last and next to be grazed for each mob in the RG system, that is, Mobl, Mob2, Mob3, Mob4, Mob5 and Mob12. This would provide the opportunity to estimate APC using the average of only 2 paddocks. A sample group of 2 mobs $($ Mob2+4) was also used because the increased number of observations might improve accuracy while still meeting practical and time constraints.

Estimates of APC for each sample set were compared with the estimates of whole-farm data using

Table 1 Various combinations of paddocks used to make up indicator sets for estimating whole-farm average pasture sample.

\begin{tabular}{lcc}
\hline Sample & Description & $\begin{array}{c}\text { No. of paddocks } \\
\text { sampled }\end{array}$
\end{tabular}

LS: The longest and shortest paddocks

in the area allocated to each $\mathbf{R G}^{\mathrm{a}}$ mob plus three SS paddocks were selected.

15

F\&B: Paddocks last and next to begrazed for each RG mob, plus the three SS paddocks. 15

G: Paddocks containing bulls on each measurement date.

\section{9}

LS-SS: The same as LS, but without SS paddocks.

2LS: The two longest and the two shortest paddocks on the farm.

Mobi The paddocks to be grazed and last grazed by the th mob

a $\quad \mathrm{RG}=$ rotational grazed, $\mathrm{SS}=$ set stocked. a pairwise correlation analysis for each measurement date.

\section{R esults}

Comparisons between APC estimated using 2 samples from each of the first and second sample sets and the estimate obtained using whole-farm measurements are shown in Figure 1.

Figure 1 Average pasture cover (APC) estimated fortnightly and monthly over winter 1992.

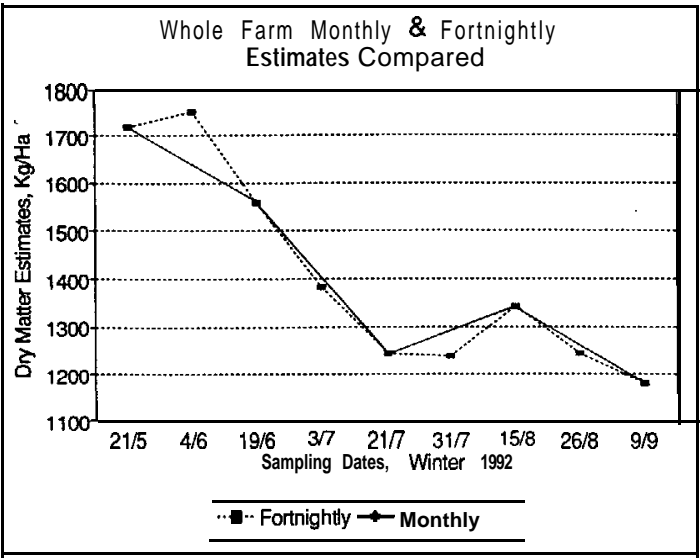

The results for indicator paddocks in the first sample set show that between $87 \%$ and $98 \%$ of variation through time in whole-farm APC could be explained by using these samples (Table 2). The 2LS option, that closest to the method of Piggot (1986), provided the poorest prediction of the whole-farm situation $(\mathbf{r}=0.93)$. The graphical comparison between whole-farm APC and the second set of indicator paddock samples showed a poorer tit than for the previous samples as demonstrated in Figure 1 for the Mob2\&4 and Mob5 samples. Not surprisingly, since they used considerably fewer measurements, indicator samples in the second sample set were less accurate predictors of changing whole farm APC ( $\mathrm{r}=0.75$ to 0.93$)$.

\section{Discussion}

The winter of 1992 was an especially difficult for collecting pasture data. Above average rainfall, and the high number of days with rain in late winter and spring, probably reduced the accuracy of RPM measurements because of the pugging of pastures. However, satisfactory results were obtained using indicator paddocks to estimate APC; the better the ability of the sample to predict, the more difficult it 
Figure 2 Average pasture cover (APC) as estimated by whole-farm measurements compared with four different paddock samples.

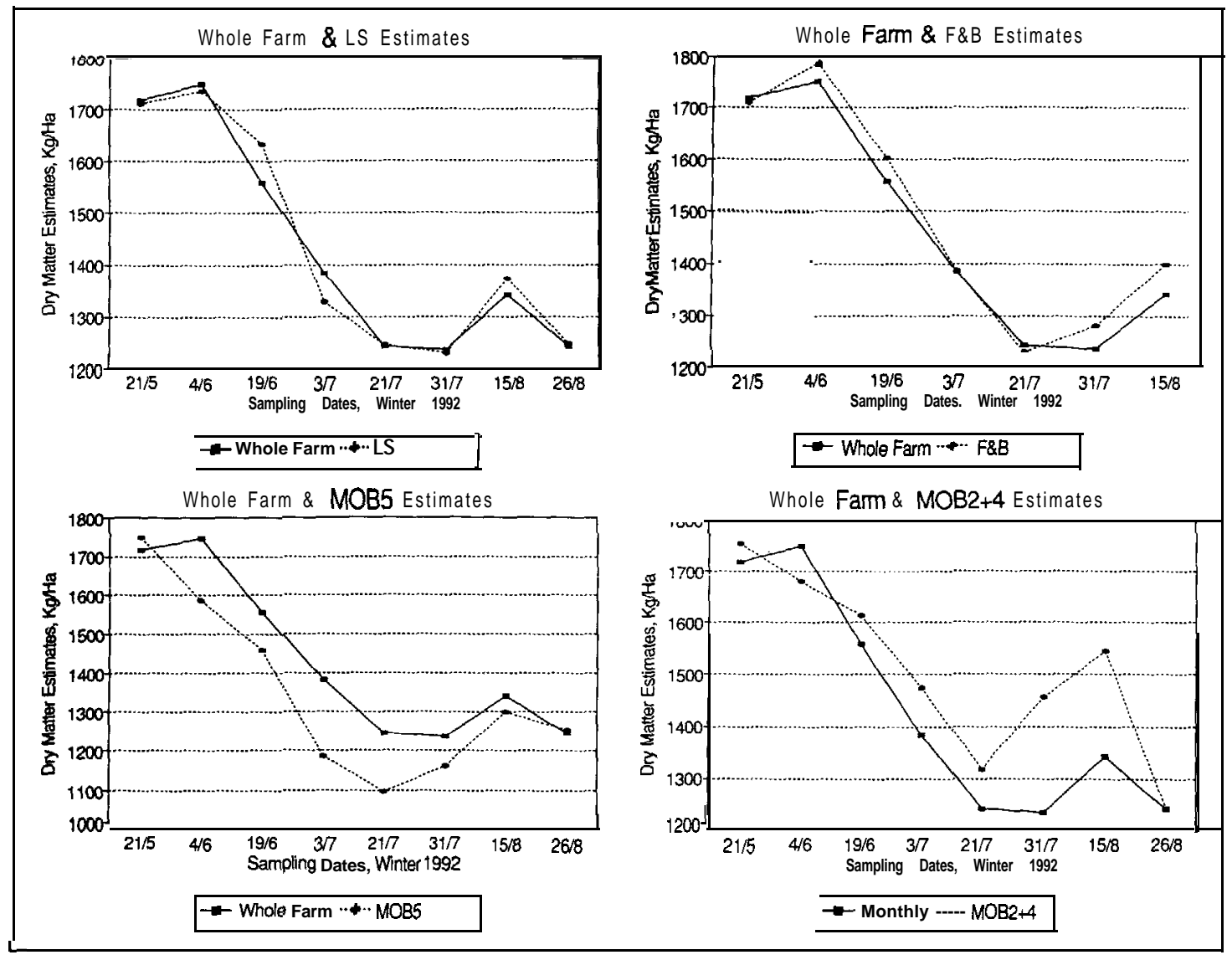

seemed to be to collect (Tables 1 and 2). Samples collected from single RG mobs could be used, but accuracy varied between samples and the best sample set was not able to be predicted unless all of the paddocks were measured.

The reliability of the estimates generally improved as the number of measurements in the indicator paddock sample increased. The averages of paired groups of paddocks ahead of and behind the RG mobs were the most practical to collect, requiring fewer measurements and less time. They also provided the opportunity to observe each group of bulls.

A system based on whole-farm measurements monthly, alternating with fortnightly indicator paddocks samples, would work as follows:

(a) Continue to assess whole-farm APC monthly as the basis for both within-season monitoring needs and to increase the historical APC database.
Table 2 Relationship (r) between whole-farm average pasture cover and indicator paddock sets during the period of pasture monitoring (21 May to 26 August 1992).

\begin{tabular}{lcc}
\hline $\begin{array}{l}\text { Indicator paddock } \\
\text { sample }\end{array}$ & $\begin{array}{c}\text { Average pasture } \\
\text { cover } \\
\text { mean } \pm \text { Sd }\end{array}$ & $\begin{array}{c}\text { Correlation } \\
\text { coefficient } \\
(r)\end{array}$ \\
\hline Whole farm & $1434 \pm 213$ & \\
First sample set & $1438 \pm 219$ & 0.9656 \\
LS & $1484 \pm 215$ & 0.9913 \\
F\&B & $1402 \pm 227$ & 0.9641 \\
G & $1452 \pm 215$ & 0.9834 \\
LS-SS & $1500 \pm 304$ & 0.9342 \\
LLS & & \\
Second sample set & $1389 \pm 281$ & 0.7507 \\
Mob1 & $1486 \pm 155$ & 0.7635 \\
Mob2 & $1694 \pm 400$ & 0.6976 \\
Mob3 & $1529 \pm 200$ & 0.9192 \\
M0b4 & $1349 \pm 229$ & 0.9330 \\
Mab5 & $1364 \pm 225$ & 0.6663 \\
Mob12 & $1510 \pm 174$ & 0.6944 \\
Mob2\&4 & & \\
\hline
\end{tabular}


(b) Use the April monthly measurement of whole-farm APC to select the mob which provides the best representation of APC and then use this as the indicator paddock mob. Paddocks ahead of and behind this mob would be measured during the grazing rotation.

(c) For each subsequent month, select the most representative mob from that month's measurements as the indicator paddock for that month's APC estimate.

To carry out these steps, the farm manager would need to apply simple graphical and/or statistical techniques, such as those readily available in most spreadsheet packages. More indicator paddocks could be added to the sample if the manager were to measure paddocks ahead of and behind the mob as RG mobs were being shifted. This practice would increase the number of observations without markedly increasing the time involved.

The additional costs of applying the indicator paddock method over a 12-month period would amount to around $\$ 300$ (Table 3). For the 100 ha Tuapaka property wintering 280 yearling bulls this equates to $\$ 1.07 /$ bull or $0.42 \mathrm{~kg} /$ bull carcass (at a schedule of $\$ 2.50 / \mathrm{kg}$ ). The total feed budget cost of $\$ 1140$, which equates to $\$ 4.1$ Oibull or about $15 \%$ of the animal health cost, is relatively low in comparison with the potential of the information to assist the farm manager minimise feed deficits and surpluses.

Table 3 Estimated data collection costs to calculate average pasture cover by the whole-farm and indicator paddock methods.

\begin{tabular}{|c|c|c|}
\hline \multirow[t]{2}{*}{ Item } & \multicolumn{2}{|c|}{ Costlbudget Annual } \\
\hline & & $\$$ \\
\hline \multicolumn{3}{|l|}{ Whole farm } \\
\hline Pasture monitoring 2.5h $@ \$ 15 / h$ & 38 & \\
\hline Data processinglinterpretation $1 \mathrm{~h}$ & & \\
\hline (1) $\$ 15 / h$ & 15 & \\
\hline Paper, power and materials & 255 & 660 \\
\hline \multicolumn{3}{|l|}{ Indicator paddock } \\
\hline Pasture monitoring lh $\$ 15 / h$ & 15 & \\
\hline $\begin{array}{l}\text { Data processinglinterpretation } 0.6 \mathrm{~h} \\
\quad \$ 15 / \mathrm{h}\end{array}$ & 9 & \\
\hline Paper, power and materials & 125 & 300 \\
\hline \multicolumn{3}{|l|}{ Equipment } \\
\hline $\begin{array}{l}\text { Plate meter (5 yr life } @ \$ 500) \\
\text { Computer (5 yr life } \$ 4000 \text { with }\end{array}$ & & 100 \\
\hline $10 \%$ use for feed planning) & & 80 \\
\hline TOTAL COST & & 1140 \\
\hline
\end{tabular}

\section{Conchsions}

A fundamental reason to increase the frequency with which pasture and animal performance data are collected is the potential to detect deviations from planned targets earlier. Knowing the magnitude of the deviation, together with experience from previous years, allows more time for grazing management to be corrected to meet production targets. The manager needs to determine whether extra returns from improved animal production offset the additional costs involved in collecting more information.

This study shows that indicator paddocks can be used to increase the frequency of farm system monitoring with only small increases in the time involved. The technique, first suggested by Piggot (1986) for dairy farmers, was found to be adaptable to a bull beef system where a larger number of animal groups were grazed. Further testing is required for the method to be adapted to sheep and beef cattle farming systems where the potential benefits, owing to topography and farm size, could be significant.

\section{REFERENCES}

Earle, D.F.; McGowan, A.A. 1979. Evaluation and calibration of an automated rising plate meter for estimating dry matter yield of pasture. Australian journal of experimental agriculture and animal husbandry 19:337-343.

Grant, D.A.; Jones, T.; Lynch, K. 1990. Outline of the Tuapaka Bull Beef Unit and the exotic cross trial. Proceedings of Tuapaka Exotic $x$ Friesian Bull Beef Field Day, Massey University: 1-4.

McRae, A.F.; Morris, S.T. 1984. Profitable bull beef systems. Tuapaka Farm Publication No. 1, Massey University.

Piggot, G.J. 1986. Methods for estimating pasture dry matter on dairy farms in Northland. Proceedings of the New Zealand Grassland Association 47: 243. 248.

Ridler, B.; Hurley, E.M. 1984. The management policy for Massey University's large herd. Proceedings of the Ruakura Farmers' Conference: 15-19. 